\title{
Manajemen Laktasi dan Kesejahteraan Ibu Menyusui
}

\author{
Inge Wattimena ${ }^{1}$, Yesiana Dwi W. Werdani \\ Fakultas Keperawatan Universitas Katolik Widya Mandala Surabaya \\ Bernadette Dian Novita, D. A. Liona Dewi \\ Fakultas Kedokteran Universitas Katolik Widya Mandala Surabaya
}

\begin{abstract}
A mother's success of lactation depends on her self-management. This study aimed to reveal the contribution of self-awareness (introspection and observation) and self-determination (competency and autonomy) as self-management factors to a lactating mother's well-being (self-actualization and positive mood). The subjects of this study were 100 mothers who had been breastfeeding for at least six weeks. A structured model was designed with self-awareness as an independent variable to dependent variable of well-being, and as an antecedent variable to self-determination affecting the dependent variable of well-being. Likert scale instruments were used. The data obtained from the questionnaires were analyzed using Structural Equation Modelling program. The models fitting the requirements showed that self-awareness had direct and indirect effects through self-determination on well-being, with a total effect of 0.924 . It could be concluded that the success of lactation achieved through the self-management has a strong influence on well-being.
\end{abstract}

Keywords: lactation management, self-awareness, self-determination, well-being

\begin{abstract}
Abstrak: Keberhasilan ibu menyusui tergantung kepada manajemen dirinya. Tujuan penelitian adalah untuk mengetahui peran sadar diri (introspeksi dan observasi) dan determinasi diri (kompetensi dan otonomi) sebagai faktor-faktor manajemen diri, dengan kesejahteraan ibu menyusui (aktualisasi potensi dan suasana hati positif). Partisipan penelitian adalah $100 \mathrm{ibu}$ yang menyusui lebih dari enam minggu. Suatu model struktur didesain, dengan variabel sadar diri sebagai variabel independen terhadap variabel dependen kesejahteraan, dan sebagai variabel anteseden untuk variabel determinasi diri yang mempengaruhi variabel dependen kesejahteraan. Data dari kuesioner (skala Likert) dianalisis dengan program Structural Equation Modelling. Model yang memenuhi syarat kesesuaian menunjukkan bahwa sadar diri mempunyai direct effect dan indirect effect melalui determinasi diri terhadap kesejahteraan, dengan total effect sebesar 0,924. Disimpulkan bahwa keberhasilan dalam menyusui yang dicapai melalui faktor-faktor manajemen diri tersebut, berpengaruh kuat pada kesejahteraan.
\end{abstract}

Kata kunci: determinasi diri, kesejahteraan, manajemen laktasi, sadar diri

Air susu ibu (ASI) menjadi salah satu program World Health Organization

\footnotetext{
* Korespondensi mengenai isi artikel ini dapat dilakukan melalui: ingewben@yahoo.com
}

(WHO) dan Pemerintah RI yang gencar dikemukakan di sektor kesehatan untuk mengurangi morbiditas dan mortalitas anak. ASI adalah sumber nutrisi yang 
primer bagi anak sejak dilahirkan sampai ia mampu mencernakan asupan lain setelah usia enam bulan. Lemak, protein, karbohidrat, vitamin, mineral, enzim, dan hormon yang terdapat dalam ASI tidak dapat digantikan oleh susu buatan industri. ASI mengandung zat-zat kekebalan yang melindungi anak dari infeksi dan penyakit kronis, serta mengurangi kemungkinan menderita gangguan kesehatan di kemudian hari seperti obesitas, diabetes, dan asthma (WHO, 2014).

UNICEF (2013) mewartakan bahwa menyusui merupakan penyelamat hidup anak yang paling murah dan efektif dalam sejarah kesehatan manusia. Yang diharapkan adalah minimal enam bulan ibu menyusui anaknya, sedapat mungkin secara eksklusif (enam bulan tanpa ada pemberian cairan/asupan lain selain ASI). Ironisnya, hanya kurang dari setengah dari anak di dunia menikmati kesempatan emas ini. Negara-negara Indonesia, Afrika Selatan, Nigeria, dan Tunesia, dilaporkan mengalami penurunan dalam angka keberhasilannya. Intervensi dari promosi kesehatan untuk menyusui menunjukkan efektivitasnya di beberapa negara. Kambodia, yang pada tahun 2000 hanya 11,7\% ibu yang berhasil menyusui lebih dari enam bulan, dengan intervensi promosi kesehatan untuk menyusui menunjukkan kenaikan sampai 74\% pada tahun 2010. Negara Zambia pun ada kenaikan dari hanya $20 \%$ pada tahun 1990 menjadi $60 \%$ pada tahun 2000.

IDAI (2009) memaparkan bahwa dalam proses menyusui, diperlukan manajemen diri ibu yang kuat dengan fokus pada diri dan pada anak. Ia memerlukan kekuatan untuk mencapai tujuan yaitu kesejahteraan diri, anak, dan keluarga.

Untuk memperdalam masalah ini, Wattimena, Nathalia, dan Marsuyanto (2012) telah melakukan penelitian secara kualitatif. Hasilnya menggambarkan bahwa faktor-faktor manajemen diri sadar diri dan determinasi diri berperan terhadap kesejahteraan ibu yang berhasil menyusui lebih dari enam bulan. Manajemen diri dimulai dari sadar diri tentang keunggulan ASI. Keadaan ini menumbuhkan afeksi positif yang kemudian berperan dalam determinasi diri untuk menentukan sikap yang kuat dan bajik. Ia memperjuangkan hak dan kepentingan anak untuk mendapat ASI, menghadapi tantangan, masalah stres fisik/psikis, kepentingan pribadi, serta godaan. Tujuan ingin dicapai untuk kepentingan ibu, anak, serta keluarga. Manajemen yang baik pada seluruh proses ini terlihat sebagai keberhasilan ibu untuk menyusui lebih dari enam bulan yang menyejahterakan ibu dan anak dalam kesehatan, kebahagiaan, komunikasi, dan kedekatan. Keadaan ini meluas sebagai kesejahteraan keluarga dan ekonomi. Ulasan ini memunculkan suatu perumusan masalah: bagaimana peran faktor-faktor manajemen sadar diri dan determinasi diri ibu yang menyusui dalam membentuk kesejahteraannya? Tujuan penelitian adalah untuk menjawab perumusan masalah ini, dan hasil analisisnya bermanfaat menambah wawasan di bidang promosi kesehatan untuk menggalakkan ibu menyusui.

Sadar diri (self-awareness) adalah status seseorang yang terfokus pada diri, dievaluasi, dan dibandingkan dengan standar dan nilai-nilai yang dianut. Ia menjadi evaluator objektif terhadap diri, dan sadar tidak nyaman bila bertentangan dengan apa yang dianutnya. Sadar diri sebagai proses kognitif berperan pada inteligensia serta efektifitas dalam kecepatan dan ketepatan berperilaku dan berargumentasi (Carlson \& Buskit, 2001).

Burnard (2014) mengemukakan bahwa pengembangan keterampilan sese- 
orang tanpa disertai sadar diri, cenderung menjadi presentasi yang tidak alami. Ia seolah hanya robot dan otomatis melakukan sesuatu tanpa sadar akan penghayatannya. Sadar diri dapat dikembangkan melalui dua perspektif, yaitu mendalami diri (introspeksi) dan mengobservasi orang lain. Kedua perspektif ini saling mengimbangi. Introspeksi untuk meningkatkan sadar diri dilakukan dengan mengamati perilaku diri. Diri diharapkan berada dalam keadaan "awas" dan mengembangkan keterampilan untuk sanggup fokus pada aksi, baik verbal maupun non-verbal. Pengembangan sadar diri juga menyebabkan semakin erat dan terampilnya berelasi, yang menurut Burns (2006) adalah penting sebagai sumber kepuasan dan kesejahteraan emosi.

Dalam proses menyusui ibu sadar akan keunggulan dirinya dalam menghasilkan ASI. Sadar dirinya mengatakan bahwa ini suatu proses yang membutuhkan kekuatan spiritual, inteligensia, dan pikiran rasional. Ia melakukan observasi pada mereka yang berhasil menyusui dan menikmati kondisi anak serta keluarga yang bahagia. Keberhasilannya menunjukkan jati diri dalam menyucikan kehidupan spiritual sesuai keyakinannya (Wattimena dkk, 2012). Sadar diri akan kekuatan spiritualitas berperan meningkatkan kesejahteraan melalui peningkatan afeksi positif bahagia, yang melindunginya terhadap depresi, serta lebih memudahkan melakukan koping (Burns, 2006). Untuk mewujudkannya perlu kekuatan determinasi diri.

Determinasi diri adalah kualitas dari yakin dan kuat untuk beraksi menuju tujuan. Yang berintegrasi dalam diri adalah motivasi dan kepribadian, serta kondisi yang mendukung proses positif tersebut melalui kompetensi, keterkaitan (relatedness), dan otonomi untuk berkarya (Ryan
\& Deci, 2009). Ketiga aspek ini adalah esensial untuk memfasilitasi fungsi yang optimal untuk bertumbuh dan berintegrasi, demikian pula untuk mengembangkan konstruksi sosial dan kesejahteraan. Dengan determinasi diri terasa suatu kebebasan untuk mengerjakan sesuatu yang menarik, penting, serta memberi semangat. Ada energi, arah, keajegan, dan keseimbangan. Motivasi dihargai tinggi karena ada konsekuensi yang menanti. Dengan perkataan lain, motivasi yang digerakkan oleh diri (motivasi intrinsik) menghasilkan sesuatu yang diharapkan. Keadaan ini menstimulasi diri untuk meningkatkan minat, semangat, dan keyakinan. Semuanya tampak dalam vitalitas dan performa optimal yang persisten, kreatif, dan mensejahterakan

Kesejahteraan atau subjective well-being adalah kata ilmiah tentang bagaimana individu mengevaluasi diri (Diener, 2008). Individu mengevaluasi diri secara umum atau global seperti hidup yang memuaskan atau perasaan yang terpenuhi, menilai dari domain kehidupan perkawinan atau pekerjaan, atau evaluasi suatu pengalaman. Ryan dan Deci (2009) berpendapat bahwa kesejahteraan bukan hanya berkisar terhadap baik atau bagusnya kehidupan, tetapi lebih ke aktualisasi potensi dengan tujuan, nilai, dan aspirasi yang membentuk kesejahteraan. Secara ringkas dapat dikatakan bahwa kesejahteraan terdiri dari tiga komponen yaitu kepuasan hidup, suasana hati positif, serta ketidakhadiran suasana hati negatif. Keseluruhannya dirangkum sebagai kebahagiaan (happiness).

Kesejahteraan ibu yang berhasil menyusui lebih dari enam bulan dalam penelitian kualitatif Wattimena dkk (2012) dilukiskan sebagai keberhasilannya memberikan asupan yang terbaik sebagai tanda kepedulian terhadap keselamatan anak. 
Ibu merasa bangga, puas, lega, rindu, dan cinta. Dengan perasaan dan pikiran positif, ia mengutarakan bahwa kemenangannya dalam keberhasilan menyusui berimbas positif pada diri dan dinamika interelasi dalam keluarga. Hasil ini sesuai dengan Diener \& Seligman (2002) yang mengatakan bahwa kesejahteraan dibentuk oleh kejadian, pengalaman, dan sumber yang berpengaruh pada kemampuan individu meraih tujuan pribadinya.

Pengalaman positif dan kesejahteraan merupakan bagian dari emosi. Emosi positif berperan pada fisiologi tubuh yang positif, kedua keadaan yang tidak terpisahkan dan saling mendukung. Emosi dan reaksi fisik berada dalam satu lingkaran yang tidak putus dan berlangsung terus. Aksi reaksi ditujukan untuk menciptakan keseimbangan jiwa raga agar terbentuk kesehatan fisik dan psikis (Carlson \& Buskit, 2001). Dalam proses menyusui terjadi interaksi emosi yang unik antara ibu dan anak yaitu melalui hisapan pada puting dan kontak kulit yang menciptakan kedekatan. Hisapan merangsang pengeluaran hormon prolaktin (hormon perangsang produksi susu), yang juga menciptakan ketenangan dalam diri ibu, serta mengurangi intensitas pengeluaran adrenalin (Altemus, 1995, dalam Dermer, 2001).

Manajemen diri yang positif berhubungan dengan sikap dan emosi yang positif. Keadaan positif merupakan elemen esensial untuk fungsi optimal karena memperluas atensi dan berpikir, meniadakan bangkitan emosi negatif, membakar semangat, membangun sumber-sumber personal, serta merupakan bibit pengembangan diri menuju kesejahteraan yang optimal (Fredrickson, 2006). Ibu menyusui perlu meregulasi diri agar berprestasi dan tujuan tercapai. Rachmah (2015) menunjukkan dalam penelitiannya bahwa keber- hasilan diperankan oleh regulasi kognitif, regulasi motivasi, regulasi perilaku, dan regulasi emosi. Selain itu ada regulasi konteks agar tujuan tercapai. Regulasi diri mereka dipengaruhi oleh situasi pencetus, karakteristik individu, dan dukungan sosialnya.

Dengan ulasan di atas ini dapat dikemukakan dasar teori untuk penelitian ini. Ibu yang berhasil untuk menyusui lebih dari enam minggu memiliki manajemen diri yang positif. Ia mengawali penataan manajemen diri dari sadar diri tentang keunggulan ASI dari berbagai aspek kehidupan. Sadar diri secara teoritis dapat ditinjau dari dua perspektif, yaitu introspeksi untuk bertanggungjawab dan mencapai tujuan, dan observasi dari percontohan dan kesehatan. Kedua perspektif ini saling mengimbangi dalam meraih tujuan. Sadar diri menumbuhkan determinasi diri yang kuat untuk berperilaku. Dalam determinasi diri ada kompetensi untuk kuat dan yakin, dan otonomi dalam hak dan kemandirian. Dengan sadar diri dan determinasi diri, tujuan diraih yaitu keberhasilan untuk menyusui lebih dari enam minggu. Ia menikmati kesejahteraan dalam konteks aktualisasi potensi untuk mencapai keberhasilan dan bermanfaat, dan suasana hati positif yang terwujud sebagai bahagia dan puas.

Hipotesis yang diajukan adalah bahwa model teoritis dinamika psikologis keterkaitan antara variabel sadar diri, determinasi diri, dan kesejahteraan yang memenuhi syarat kesesuaian model, menunjukkan bahwa: sadar diri secara langsung berperan positif dan signifikan terhadap kesejahteraan ibu menyusui; sadar diri secara tidak langsung, yaitu sebagai anteseden dari determinasi diri, berperan positif dan signifikan terhadap kesejahteraan ibu menyusui; dan pengaruh sadar diri secara tidak langsung 
terhadap kesejahteraan yaitu melalui pengaruhnya terhadap determinasi diri, adalah lebih besar daripada pengaruh langsungnya terhadap kesejahteraan.

\section{Metode}

Variabel Penelitian. dalam penelitian ini terdapat tiga variabel penelitian yaitu: (1) Variabel sadar diri dengan sub-variabel introspeksi dan observasi; (2) variabel kesejahteraan dengan sub-variabel aktualisasi potensi dan suasana hati positif; dan (3) variabel determinasi diri dengan subvariabel kompetensi dan otonomi.

Partisipan Penelitian. Seratus partisipan yang diambil secara purposive sampling adalah perempuan menyusui yang bayinya berumur lebih dari enam minggu dan bersedia untuk berpartisipasi dalam penelitian. Batas umur ini ditentukan berdasarkan asumsi bahwa proses penguncian mulut anak pada puting ibu (latched on) terjadi setelah enam minggu (Women's Health, 2014). Setelah penguncian, diasumsikan bahwa hubungan batin/perasaan ibu dan anak serasi dan erat (Seligman \& Csikszentmihalyi, 2000), dengan harapan bahwa pola rasa, pola pikir, dan pola sikap dalam sadar diri, determinasi diri, dan kesejahteraan ibu sudah semakin mantap.

Karakteristik demografi partisipan: 5\% partisipan berpendidikan sekolah dasar, $15 \%$ berpendidikan sekolah menengah pertama, 29\% berpendidikan sekolah menengah atas, dan $51 \%$ berpendidikan sarjana; rerata umur partisipan adalah 28.83 tahun; partisipan yang bekerja dan yang tidak bekerja berjumlah sama; umur rerata anak adalah 9,74 bulan; dan 40\% bayi diberi asupan tambahan sebelum berumur enam bulan.

Instrumen penelitian. Masing-masing variabel dibuat kuesioner berskala Likert;
(1) Variabel sadar diri dengan sub-variabel introspeksi (bertanggung jawab dan bertujuan) dan observasi (dari contoh dan kesehatan); (2) variabel kesejahteraan dengan sub-variabel aktualisasi potensi (berhasil dan bermanfaat) dan suasana hati yang positif (bahagia dan puas); dan (3) variabel determinasi diri dengan subvariabel kompetensi (kuat dan yakin) dan otonomi (menentukan hak dan mandiri).

Aitem-aitem instrumen diuji validitasnya melalui uji validitas butir-total (menggunakan formula koefisien korelasi product moment dari Pearson), dan uji reliabilitas alpha dari Cronbach (dengan program SPSS 13.0). Reliabilitas variabel sadar diri adalah 0,898, determinasi diri 0,918, dan kesejahteraan 0,924.

Analisis data penelitian. Melalui model struktur yang dibentuk oleh tiga model pengukuran masing-masing variabel dengan sub-variabelnya, data dianalisis menggunakan structural equation modeling (SEM) yang dikomputasi dengan program IBM SPSS AMOS versi 21. Model pengukuran (measurement model): Setiap model pengukuran variabel sadar diri, determinasi diri dan kesejahteraan diuji kuatnya model melalui confirmatory factor analysis (diuji kesesuaian model dan nilai lambda) dan reliabilitas model. Ketiga model pengukuran mempunyai demensidemensi yang masing-masing valid dan reliabel serta unidemensi dalam menjelaskan variabel latennya.

Model struktur, dibentuk oleh ketiga model pengukuran variabel. Variabel kesejahteraan berkedudukan sebagai variabel dependen; variabel sadar diri dan variabel determinasi diri sebagai variabel independen. Variabel sadar diri mempunyai pengaruh langsung terhadap variabel kesejahteraan, dan pengaruh tidak langsung yaitu sebagai variabel anteseden dari variabel determinasi diri terhadap kesejah- 
teraan. Tehnik pengolahan data model sturktur diuji kesesuaian model serta kekuatan regresinya.

\section{H a s i 1}

Model struktural teoritis dinamika psikologis keterkaitan antara variabelvariabel sadar diri, determinasi diri, dan kesejahteraan, setelah dimodifikasi, memenuhi syarat kesesuaian model (fit). Modifikasi dilakukan dengan menghubungkan eror antar demensi variabel kesejahteraan, dan eror kesejahteraan serta eror determinasi diri. Keadaan ini merupakan kelemahan dari model yang fit ini.

Efek sadar diri terhadap kesejahteraan secara langsung adalah sebesar 0,359, sedangkan efek tidak langsung yaitu melalui pengaruhnya terhadap determinan diri adalah sebesar 0,565, dengan efek total mencapai 0,924. Hasil-hasil ini menunjukkan bahwa hipotesis yang diajukan terbukti.

Normalitas sebaran univariat ketiga variabel adalah normal, sedangkan dalam bentuk multivariat sebarannya adalah moderately non normal. Ini menunjukkan bahwa hasil penelitian ini kurang kuat dalam menggambarkan populasi.

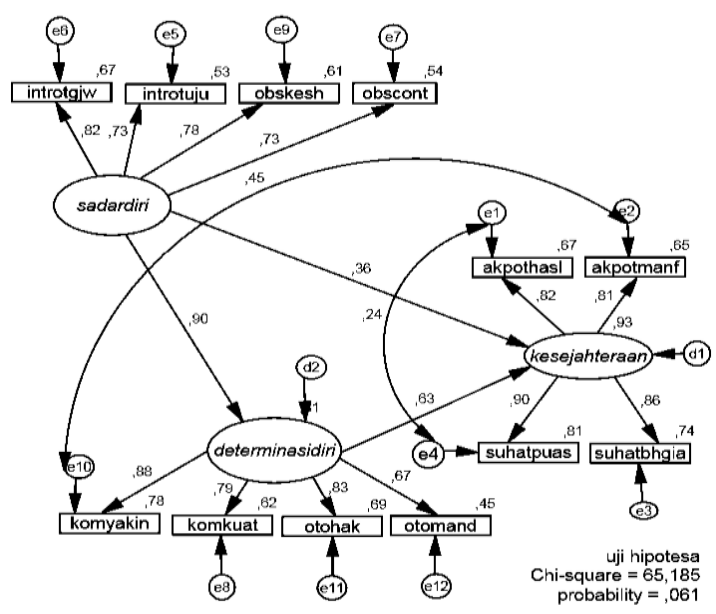

Gambar 1: Model struktur yang fit

\section{Diskusi}

Partisipan. Umur rerata partisipan 29 tahun, sebagian besar berpendikan sarjana, mempunyai anak dengan rerata umur 10 bulan, dan berjenjang sarjana. Jumlah partisipan yang bekerja dan tidak bekerja adalah sama, keadaan mana menguntungkan dari segi terdapatnya kesempatan yang cukup untuk menyusui. Administrator KPPPARI (2014) menunjukkan bahwa ibu bekerja di perkotaan adalah $45 \%$, dan di pedesaan $51 \%$.

Enampuluh persen partisipan tidak memberi asupan tambahan sebelum enam bulan, yang berarti bahwa mereka memberi ASI eksklusif. Keadaan ini mendukung program WHO (2012) yang mempunyai target sebesar $80 \%$ ibu menyusui secara eksklusif pada 2025 (global rate yang tercapai pada 2012 adalah $37 \%$ ), dan program pemerintah, yang berdasarkan laporan Sentra Laktasi Indonesia (2011) menunjukkan bahwa pemberian ASI eksklusif pada bayi di bawah usia dua bulan (berdasarkan Survei Demografi dan Kesehatan Indonesia tahun 2006-2007) hanya mencakup $67 \%$ dari total bayi yang ada. Persentase tersebut menurun seiring dengan bertambahnya usia bayi, yakni $54 \%$ pada bayi usia 2-3 bulan dan 19\% pada bayi usia 7-9 bulan. Yang lebih memprihatinkan, $13 \%$ bayi di bawah dua bulan telah diberi susu formula, dan satu dari tiga bayi usia 2-3 bulan telah diberi makanan tambahan.

Data Polman (2014) menunjukkan bahwa berdasarkan hasil penelitian World Breastfeeding Trends Initiative (2012), hanya $27,5 \%$ ibu di Indonesia yang berhasil memberi ASI eksklusif selama 6 bulan. Data Riset Kesehatan Dasar 2013 menunjukkan cakupan ASI di Indonesia hanya $42 \%$. Dengan hasil tersebut, Indonesia berada di peringkat 49 dari 51 negara yang mendukung pemberian ASI eksklusif. 
Sadar diri: Introspeksi untuk bertanggung jawab mempunyai bobot faktor tertinggi (0.82), atau merupakan demensi terkuat dari sadar diri. Ismail, Muda, dan Bakar (2013) berdasarkan penelitiannya menunjukkan bahwa intensi untuk menyusui dan menyadari pentingnya menyusui, berkorelasi secara signifikan. Keberhasilan proses yang menunjukkan suatu tanggung jawab, juga didukung keluarga dan perawat. Perawat sebagai petugas kesehatan mempunyai peran sebesar 21,3\% dalam keberhasilan ibu untuk menyusui secara eksklusif, sedangkan 22,9\% dipengaruhi oleh peran media cetak (Astuti, 2013). Melalui intervensi ini tumbuhlah kesadaran keluarga untuk bersama mendukung keberhasilan pemberian ASI sedapatnya secara eksklusif. Dengan sadar diri yang tinggi, diharapkan tumbuh perhatian, motivasi, kesiapan menerima informasi dan latihan keterampilan, dan kemudian melakukannya untuk mencapai tujuan.

Bobot faktor introspeksi agar mencapai tujuan sebagai demensi sadar diri adalah 0,74. Wattimena dkk (2012) memaparkan tentang introspeksi ibu bahwa beranak berarti siap dengan segala kerepotannya. Mau berkorban, memahami, dan berubah dalam menghadapi tantangan, menghadapi godaan, memperjuangkan hak dan kepentingan anak, menghadapi stres fisik dan psikis, serta menghadapi kepentingan pribadinya. Dengan setiap kali melakukan proses introspeksi bila ada kesulitan dalam menyusui, ibu semakin kuat dalam bersikap dan mengatakan "saya pasti bisa."

Observasi contoh dan kesehatan merupakan demensi sadar diri dengan bobot faktor 0,71. Dengan observasi terjadi proses pembelajaran yang memotivasi suatu perilaku, yang disebut Bandura (1971, dalam Petri, 1985) sebagai suatu social learning theory. Kondisi sosial yang diobservasi menjadi model yang kemudian dipelajari. Bagaimana ia kemudian berfungsi tergantung pada interaksi antara perilaku yang spesifik dan kondisi yang mengontrolnya. Dalam Wattimena dkk. (2012) dipaparkan tentang observasi melalui media pengetahuan dan sosial, serta melalui sharing dengan keluarga dan teman. Observasi kepada ibu-ibu ASI yang hebat walaupun bekerja, atau para pendonor ASI, membuat ibu pasca melahirkan semakin sadar diri tentang kesempatan yang ada.

Sebanyak $70 \%$ partisipan bersadar diri tinggi. Hasil ini mendukung penelitian Wattimena dkk. (2012) yang menunjukkan perspektif kekuatan ibu menyusui dengan sadar diri; (1) untuk menyusui. Ibu berfokus pada proses yang disadari sebagai tugas wajib tanpa pamrih dan terbaik untuk anak. Niat dan mau mengatur diri adalah kunci keberhasilan; (2) untuk memaknai ASI sebagai sumber gizi yang hebat, yang mensuport anak dengan kekebalan, serta sarana terbinanya kedekatan lahir batin ibu dan anak; dan (3) bahwa kekuatan spiritual dalam ASI memanusiakan anak manusia sesuai petunjuk Allah.

Determinasi diri. Kompetensi untuk yakin dapat melakukan apa yang diikhtiarkan mempunyai bobot faktor tertinggi $(0,89)$. Yakin dan leluasa menggunakan hak adalah demensi terkuat dari determinasi diri. Keadaan ini diterangkan oleh Bandura (1997) yang mengatakan bahwa salah satu faktor dari determinasi diri adalah efikasi diri atau bagaimana individu berfungsi secara efektif karena ia yakin dapat melakukannya. Dalam efikasi diri ada kompetensi untuk melaksanakan, mempertahankan, dan yakin untuk mencapai keberhasilan. Efikasi diri berkorelasi positif dengan keberhasilan menyusui 
minimal selama enam minggu (Dennis \& Fauz, 1999). Melalui BSES (Wilhelm, Rodehorst, Stefans, \& Hertzog, 2008) ditunjukkan bahwa semakin tinggi intensi dan efikasi diri, semakin besar kemungkinan untuk berhasil menyusui minimal selama enam bulan.

Kompetensi untuk kuat menjalankan apa yang diikhtiarkan juga berbobot tinggi $(0,73)$ Seorang ibu (Wattimena dkk., 2012) mengatakan bahwa kekuatan itu "merubah pribadi seseorang, karena egoisnya berkurang." Kepentingan pribadi dikesampingkan, dan nyenyaknya tidur malam dengan ikhlas ditukar untuk menyusui. Kurniawan (2013) menunjukkan bahwa dari 146 partisipan, 35,3\% di antaranya memiliki keinginan kuat dan $28 \%$ mempunyai kepercayaan kuat untuk memberi ASI secara eksklusif.

Kompetensi menunjukkan adanya penguatan (empowerment) untuk mencapai tujuan. Jung, So, dan Eun (2007) melakukan kuasi eksperimen pada ibu-ibu tiga hari pasca melahirkan. Pada kelompok 30 ibu dengan intervensi program penguatan, terjadi keberhasilan menyusui dan pengurangan keluhan yang signifikan, dibandingkan dengan kelompok tanpa intervensi. Menurut Kim (2009) efek dari program penguatan meningkatkan keingin-tahuan masalah menyusui, keyakinan dan keinginan untuk melakukan, serta keterampilan dalam menyusui. Intervensi dilakukan sebelum dan sesudah melahirkan.

Ada optimisme (Seligman \& Csikszentmihalyi, 2000) dalam keyakinan untuk berani mengambil inisatif, melakukannya, mencapai tujuan, serta menghadapi rintangan dengan kemampuan diri. Partisipan dalam penelitian Wattimena dkk (2012) mengatakan bahwa semula ASI tidak dapat langsung keluar dengan deras. Dengan optimisme dan menyusui sesering mungkin, ASI semakin banyak dipro- duksi, dan "tidak akan pernah macet sumbernya."

Otonomi menggunakan hak dalam berperilaku merupakan demensi kuat dari determinasi diri $(0,87)$. Suatu penelitian Shroff dkk. (2011) pada 600 ibu menyusui antara 3-5 bulan di India menunjukkan bahwa semakin tinggi hak otonomi (dalam aspek mengambil keputusan, bebas berkarya, mempunyai hak finansial, dan bebas dari kekerasan), semakin berhasil ibu menyusui. Selain ini, partisipasi tinggi dalam mengambil keputusan dan berhak menentukan keuangan keluarga, menunjang pertumbuhan dan kesehatan bayi.

Kent (2006) mengatakan bahwa anak mempunyai hak untuk mendapat ASI, dan ibu mempunyai hak untuk menyusui tanpa dihalangi oleh siapapun. Suatu bentuk otonomi adalah penolakan ibu terhadap pemberian susu formula kepada anaknya. Partisipan dalam penelitian Wattimena dkk (2012) mengatakan bahwa susu formula tidak dapat menggantikan ASI, dan bahwa politik perdagangan seperti di iklan susu sebenarnya adalah pembodohan masyarakat. Hak otonomi lain adalah pernyataan "saya akan menyusui selama mungkin."

Sebagian besar partisipan penelitian berdeterminasi tinggi. Dengan niat, yakin, percaya diri, dan semangat, ibu menghimpun kekuatan positif, yang membentuk sikap yang memungkinkan ia melihat secara realistik keadaan diri dan lingkungannya. Mau berkorban, memahami, merubah, mengalahkan ego, dan menyetarakan, membuat tekad ibu semakin bulat untuk menyusui selama dibutuhkan. Dengan demikian ia semakin yakin akan kemampuannya dan mempunyai kontrol terhadap kehidupannya. Dalam batas kemampuannya ia sanggup mengerjakan apa yang menjadi harapan, rencana, dan tantangannya (Wattimena dkk., 2012). 
Kesejahteraan. Dalam measurement model kesejahteraan, dilakukan modifikasi agar model fit, dengan menghubungkan aktualisasi potensi untuk berhasil dengan suasana hati puas dan bangga. Hubungan ini secara teoritis dapat diterangkan dengan teori Diener (2008). Ia mengatakan bahwa evaluasi diri yang positif terhadap keberhasilan oleh potensi diri, menghasilkan rasa puas dan bahagia yang menyejahterakan.

Suasana hati positif puas dan bahagia merupakan demensi terkuat dari kesejahteraan. Wattimena dkk. (2012) mengungkapkan bahwa perasaan puas, bangga, lega, rindu, dan cinta, diutarakan dalam nyanyian, ungkapan, dan sentuhan bahagia sewaktu menyusui. Isen (2000) berpendapat bahwa suasana hati yang positif membuat pola pikir fleksibel, kreatif, integratif, terbuka terhadap informasi, dan efisien. Suasana positif ini berperan terhadap peningkatan kegiatan otak, yang diharapkan berperan pada regulasi fisiologi tubuh yang positif, antara lain dalam berproduksi ASI.

Suasana hati positif diteliti Meneses (2013) pada pada 311 perempuan menyusui. Tujuannya adalah meneliti emosi dalam proses menyusui, dan menganalisis sejauh mana hubungannya dengan proses kognisi. Hasilnya menunjukkan bahwa suasana hati, sebagai suatu reaksi emosi, merupakan suatu instink reaksi emosional daripada suatu keputusan yang rasional, dan independen dari proses kognisi.

Aktualisasi potensi untuk berhasil dan bermanfaat berbobot faktor tinggi terhadap kesejahteraan. Wattimena dkk (2012) memaparkan bahwa aktualisasi potensi antara lain adalah dalam keberhasilan menyusui lebih dari enam bulan, yang menunjukkan kekuatan ibu dalam sikap yang kuat dan bajik menghadapi tantangan. "Minta tolong"nya anak agar men- dapat pemenuhan kebutuhan, terpenuhi dengan baik. Ibu membuktikan tentang potensinya untuk memberi hak dan memprioritaskan kepentingan anak untuk mendapat ASI.

Sebanyak $80 \%$ partisipan berkesejahteraan tinggi. Mereka berhasil mewujudkan aktualisasi potensi dan bersuasana hati positif. Ada kesejahteraan ganda karena terbentuk kesejahteraan anak dan ibu (Wattimena dkk., 2012). Selain kebutuhan anak terpenuhi dengan baik, ibu juga mendapat keuntungan pribadi. Pada ibu dan anak terbentuk kerjasama lahir dan batin dalam konteks "saling" yang semakin erat. Kesejahteraan mereka menumbuhkan kesejahteraan keluarga dan lingkungan kehidupan.

Sadar diri dan Determinasi diri. Korelasi sadar diri dengan determinasi diri adalah tinggi $(0,85)$ yang menandakan bahwa kedua variabel tidak bersifat independen, tetapi mempunyai hubungan kausalitas yang tinggi. Meskipun demikian, validitas diskriminannya tercapai, yang menandakan bahwa kedua variabel ini tetap merupakan dua hal yang berbeda dan saling mendukung.

Sadar diri dan Kesejahteraan. Peran sadar diri terhadap kesejahteraan secara langsung dalam penelitian adalah kecil $(0,36)$. Dengan berbekal sadar diri saja, belum ditunjukkan suatu kekuatan atau motivasi untuk beraksi atau berbuat, sehingga perannya pada hasil yang menyejahterakan belum dapat dirasakan.

Sadar diri tentang keunggulan ASI (Wattimena, 2012) berwacana; (1) ASI mempunyai banyak kelebihan, praktis, dan ekonomis; (2) sadar diri untuk menyusui: "Menjadi ibu adalah pilihan, mau menyusui dengan mau berkorban, mau memahami, mau berubah, serta menyetarakan", dan (3) sadar diri tentang kekuatan spiritual dalam ASI: "ASI adalah 
berkat Allah, waktu melahirkan ASI keluar dengan sendirinya, suatu mujizat Allah."

Kesadaran diri tinggi untuk menyusui selama proses kehamilan, menjadi prediktor baik pada keberhasilan menyusui minimal selama enam bulan. Meskipun berprediksi tinggi, tetapi tidak adanya intensi untuk menyusui akan berbanding terbalik dengan keberhasilan untuk menyusui minimal selama enam bulan (Rempel, 2004). Keadaan ini menunjukkan bahwa sadar diri saja tanpa intensi atau determinasi diri, belum tentu menuju keberhasilan dan kesejahteraan.

Determinasi diri dan Kesejahteraan. Dalam model structural, variabel determinasi diri (sub-variabel yakin untuk melakukan), terhubung dengan variabel kesejahteraan (sub-variabel aktualisasi potensi). Ryan dan Deci (2009) mengatakan bahwa keyakinan adalah suatu bentuk motivasi intrinsik yang memfasilitasi diri untuk berkarya secara optimal, dan menghantarkan individu menuju kesejahteraan karena terwujudnya aktualisasi potensi diri yang bermanfaat. Aktualisasi diri dalam hierarchy of needs dari Maslow (1968, dalam Kiaei, 2014) menduduki jenjang pola kebutuhan manusia yang tertinggi (setelah kebutuhan fisiologis, keamanan, kasih, dan harga diri). Penelitian Kiaei menunjukan bahwa aktualisasi potensi diri berkorelasi positif dan signifikan dengan kesejahteraan.

Sadar diri, Determinasi diri, dan Kesejahteraan. Dalam model struktural, efek total sadar diri terhadap kesejahteraan melalui determinasi diri adalah besar $(0,924)$. Kenyataan ini menunjukkan bahwa sadar diri dan determinasi diri bersama-sama berperan besar pada kesejahteraan. Deci dan Ryan (2008) memaparkan bahwa motivasi manusia, pengembangan diri, dan kesejahteraan dilandasi oleh determi- nasi diri. Yang menentukan berhasil tidaknya motivasi adalah kompetensi, otonomi, dan keterhubungan. Dengan determinasi diri, timbullah suatu sikap berperilaku. Wattimena dkk. (2012) memaparkan bahwa sikap yang kemudian terbentuk adalah sikap yang kuat dan bajik menghadapi tantangan. Mau berkorban, memahami, merubah, mengalahkan ego, dan menyetarakan, membuat tekad ibu semakin bulat untuk menyusui selama dibutuhkan. Godaan dan stres fisik maupun psikis ditepis dengan bajik. Kesejahteraan dalam kesehatan, kebahagiaan, komunikasi, dan kedekatan antara ibu dan anak, kemudian menciptakan kesejahteraan keluarga dan lingkungan kehidupan.

Paparan Renwick (1996) membenarkan hasil penelitian ini. Ia berpendapat bahwa individu menikmati kesejahteraan apabila ia dapat mencapai aspirasinya yang ia sadari sebagai sesuatu yang menarik perhatiannya. Dengan determinasi diri ia memilih sendiri secara otonom suatu kesempatan yang merdeka dari hambatan atau tekanan untuk merealisasikannya. Kemerdekaan ini tidak terlepas dari pengalaman hidup. Tanpa pengasuhan dan dukungan dari keluarga atau lingkungan, individu tidak dapat mengembangkan kapasitas untuk membuat rencana dan menerapkan determinasi diri di dalam kehidupannya. Dukungan pada keberhasilan untuk menyusui (Wattimena dkk., 2012) didapat dari suami/keluarga serta media pengetahuan/sosial yang mengajarkan, membimbing, dan mendampingi ibu sewaktu menyusui.

\section{Kesimpulan}

Kesimpulan: Proses menyusui yang perlu dilakukan dan ditaati ibu pasca melahirkan, paling sedikit selama enam bulan dan sedapat mungkin secara eksklusif, tidaklah mudah. Penelitian ini 
menunjukkan bahwa ibu perlu mempunyai manajemen diri yang kuat dalam sadar diri dan determinasi diri. Sadar diri (untuk introspeksi dan observasi) memicu determinasi diri (dalam kompetensi dan otonomi), yang menyejahterakan ibu. Ia menunjukkan aktualisasi potensinya untuk berhasil dan bermanfaat, dalam suasana hati yang puas dan bahagia.

\section{Saran}

Tatanan psikologis hasil penelitian ini disarankan untuk diimplementasikan dalam program Promosi Kesehatan, baik untuk masalah ibu menyusui maupun masalah kesehatan lain. Kelemahan struktur model penelitian disarankan agar dikaji lebih lanjut dalam penelitian lain.

\section{Kepustakaan}

Administrator KPPPARI. 2014. Kementerian pemberdayaan perempuan dan perlindungan anak Republik Indonesia. Artikel. Diunduh dari: http://www. kemenpppa.go.id tanggal 6 Maret 2015.

Astuti, I. (2013). Determinan pemberian ASI eksklusif pada ibu menyusui. Jurnal Health Quality, 4(1), 1-76.

Bandura, A. (1997). Self-efficacy, the exercise of control. New York: Freeman.

Burnard, P. (2014). Learning human skills. An experiential and reflective guide for nurses and health care professionals. Elsevier Science Ltd, Oxford.

Burns, G. W. (2006). Naturally happy, naturally healthy: the role of the natural environment in well-being. Dalam F.A. Huppert, N. Baylis, \& B. Keverne (Eds.): The Science of Wellbeing. Oxford University Press.

Carlson, N. R., \& Buskit, W. (2001). The science of behavior. London: Allyn \& Bacon.
Deci, E. L., \& Ryan, R. M. (2008). Facilitating optimal motivation and psychological well-being. Canadian Psychology, 49(1), 14-23. http://dx.doi.org/ 10.1037/0708-5591.49.1.14

Dennis, C. L., \& Faux, S. (1999). Development and psychometric testing of the Breastfeeding Self-Efficacy Scale. Research in Nursing Health, 22, 399-409. http://.dx.doi.org/10.1002/(SICI)109824 0X(199910)22:5<399::AID-NUR6>3.0.C O;2-4.

Dermer, A. (2001). A well-kept secret: breastfeeding's benefits to mothers. New Beginnings, 8(4), 124-127. Diunduh dari: http://www.llli.org/nb/ nbjulaug01p124.html.

Diener, E. 2008. The science of optimal happiness. Boston: Blackwell Publishing.

Diener, E., \& Seligman, M. (2002). Very happy people. Psychology Science, 13(1), 81-84. Diunduh dari: http:// www.ncbi.nlm.nih.gov/pubmed/11894 851

Fredrickson, B. L. (2006). The broadenand-build theory of positive emotions. Dalam F.A. Huppert, N. Baylis, \& B. Keverne (Eds.): The science of well-being. Oxford University Press.

Ikatan Dokter Anak Indonesia/IDAI. (2009). Air susu dan tumbuh kembang anak. Artikel. Diunduh dari: http:// www.idai.or.id tanggal 19 Desember 2009.

Isen, A. M. (2000). Positive affect and decision making. Handbook of emotions. Guildbook Press, New York.

Ismail, T. A. T., Muda, W. M. W., \& Bakar, M. I. (2013). Intention of pregnant women to exclusively breastfeed their infants. Journal of Child Health Care, Sage Journals, http://dx.doi.org/ 10.1177/1367493512473857J. 
Jung, S. K., So, Y. C., \& Eun, J. R. (2007). Effects of a breastfeeding empowerment programme on Korean breastfeeding mothers: A quasi-experimental study. Journal of Nursing Studies, 20(9), 103-114.

Kiaei, Y. A. (2014). The relationship between metacognition, self-actualization, and well-being. (Dissertation. FIU Digital Commons, FIU Electronic Theses and Dissertations). Florida International University.

Kim, Y. (2009). Effects of a breastfeeding empowerment program on exclusive breastfeeding. Journal Korean Acad Nurs, 39(2), 279-287.

Kurniawan, B. (2013). Determinan keberhasilan pemberian air susu ibu eksklusif. Jurnal Kedokteran Brawijaya, 27(4), 236-240.

Meneses, G. D. (2013). An emotional instinct. Breastfeeding medicine, 8(2), 191-197.

Petri, H. L. (1985). Motivation: theory and research. Wadsworth Publishing Company.

Polman, B. (2014). Ibu bekerja dan menyusui. Diunduh dari: http://polman.babel. ac.id tanggal 2 Maret 2015.

Rachmah, D. N. (2015). Regulasi diri dalam belajar pada mahasiswa yang memiliki peran banyak. Jurnal Psikologi, 42(1), 61-77. Diunduh dari: http://jurnal.ugm.ac.id/jpsi/article/vie $\mathrm{w} / 6943$

Rempel, L. A. (2004). Factors influencing the breastfeeding decisions of long term breastfeeders. Journal of Human Lactation, 20, 306-317.

Renwick, R., Brown, \& I., Nagler, M. (1996). Quality of life in health promotion and rehabilitation. Sage Publications Inc.
Ryan, R. M., \& Deci, E. L. (2009). Selfdetermination theory and well-being. Research review. Diunduh dari: http://www.bath.ac.uk tanggal 6 Desember 2010.

Seligman, M. E. P., \& Csikszentmihalyi, M. (2000). Positive psychology. American Psychologyst, 55, 5-14.

Sentra Laktasi Indonesia. (2011). Menyusui langka perlindungan. Artikel. Diunduh dari: http://sentralaktasi.multiply.com/ tanggal 13 Oktober 2011.

Shroff, M.R., Griffiths, P.L., Suchrindan, C., Nagalla, B., \& Bentley, M. (2011). Does maternal autonomy influence feeding practices and infant growth in rural India? Social Science \& Medicine, 73(3), 447-455.

Unicef. 2013. Breastfeeding is the cheapest and most effective life-saver in history. Press release. Diunduh dari: http:// www.unicef.org/ tanggal 20 November 2014.

Wattimena, I., Nathalia, L.S., \& Marsuyanto, Y. (2012). Kekuatan psikologis ibu menyusui. Jurnal Kesehatan Masyarakat Nasional, KesMas, 7(2), 56-62.

WHO. (2009). Health topics, the importance of breastfeeding. Diunduh dari: http:// www.who.int/ tanggal 12 Februari 2015.

WHO. (2014). Nutrition, exclusive breastfeeding. Diunduh dari: http://www. who.int/ tanggal 12 Februari 2015.

Wilhelm, S. L., Rodehorst, T. K., Stepans, M. B., \& Hertzog, M. (2008). Influence of intention and self-efficacy levels on duration of breastfeeding for mid-west rural mothers. Applied Nursing Research, 21(3), 123-130.

Women's Health. (2014). Breastfeeding: learning how to breastfeed. Diunduh dari: http://www.womenshealth.gov tanggal 8 Maret 2015. 